\title{
Wild birds and urban pigeons as reservoirs for diarrheagenic Escherichia coli with zoonotic potential ${ }^{\S}$
}

\author{
Clarissa A. Borges ${ }^{1 \star}$, Marita V. Cardozo', \\ Livia G. Beraldo ${ }^{1}$, Elisabete S. Oliveira ${ }^{1}$, \\ Renato P. Maluta ${ }^{2}$, Kaline B. Barboza ${ }^{1}$, \\ Karin Werther ${ }^{1}$, and Fernando A. Ávila ${ }^{1}$ \\ ${ }^{1}$ Department of Veterinary Pathology, Faculty of Agricultural and \\ Veterinary Sciences, São Paulo State University (UNESP), Jaboticabal, \\ São Paulo 14884900, Brazil \\ ${ }^{2}$ Department of Genetics, Evolution and Bioagents, Institute of Biology, \\ State University of Campinas (UNICAMP), Campinas, São Paulo \\ 13083872, Brazil \\ (Received Oct 12, 2016 / Revised Jan 9, 2017 / Accepted Jan 12, 2017)
}

In order to describe the role of wild birds and pigeons in the transmission of shiga toxigenic Escherichia coli (STEC) and enteropathogenic Escherichia coli (EPEC) to humans and other animals, samples were collected from cloacae and oropharynx of free-living wild birds and free-living pigeons. Two STEC $(0.8 \%)$ and five EPEC strains $(2.0 \%)$ were isolated from wild birds and four EPEC strains (2.0\%) were recovered from pigeons. Serogroups, sequence types (STs) and virulence genes, such as saa, iha, lpf $A_{\mathrm{O} 113}, e h x \mathrm{~A}, e s p \mathrm{~A}, n l e \mathrm{~B}$ and $n l e \mathrm{E}$, detected in this study had already been implicated in human and animal diseases. Multidrug resistance (MDR) was found in 25.0\% of the pigeon strains and in $\mathbf{5 7 . 0 \%}$ of the wild bird strains; the wild birds also yielded one isolate carrying extended-spectrum $\beta$-lactamases (ESBLs) gene $b \boldsymbol{l a}_{\mathrm{CTX}-\mathrm{M}-8 \text {. The high varia- }}$ bility shown by PFGE demonstrates that there are no prevalent $E$. coli clones from these avian hosts. Wild birds and pigeons could act as carriers of multidrug-resistant STEC and EPEC and therefore may constitute a considerable hazard to human and animal health by transmission of these strains to the environment.

Keywords: EPEC, antibiotic resistance, STEC, virulence genes, zoonotic pathogens

\section{Introduction}

Enteropathogenic Escherichia coli (EPEC) and Shiga toxinproducing Escherichia coli (STEC) are foodborne zoonotic pathogens that belong to the category of diarrheagenic $E$. coli that can cause disease in humans. EPEC is responsible

*For correspondence. E-mail: clarissa.araujob@gmail.com; Tel.: +1-510417-7025

${ }^{8}$ Supplemental material for this article may be found at http://www.springerlink.com/content/120956.

Copyright (c) 2017, The Microbiological Society of Korea for causing severe diarrhea and is characterized by its ability to generate attaching and effacing (A/E) lesions in the intestinal epithelium; the generation of these lesions has been shown to be mediated by the eae gene (Kaper et al., 2004). Some EPEC strains contain an EPEC adherence factor (EAF) plasmid and are referred to as "typical EPEC" (tEPEC) strains, whereas EPEC strains lacking this EAF plasmid are referred to as "atypical EPEC" (aEPEC) strains (Trabulsi et al., 2002).

STEC strains are mostly responsible for potentially lifethreatening diarrhea with complications such as hemorrhagic colitis (HC) and diarrhea-associated hemolytic-uremic syndrome (HUS). STEC strains produce specific cytotoxins (Shiga toxins) such as Stx1 and Stx2, and some strains can also cause attaching and effacing (A/E) lesions (Kaper et al., 2004). Other putative virulence factors are usually present in pathogenic E. coli strains. Some of them, such as the EhxA enterohemolysin, and putative adhesins encoded outside of the enterocyte effacement (LEE) locus, such as lpfA, nleB, and nleE, have been found in association with severe clinical disease in humans (Boerlin et al., 1999; Afset et al., 2006; Coombes et al., 2008).

Studies reported that the intestinal microbiota of wild birds and urban pigeons includes STEC and EPEC, as well as multidrug-resistant (MDR) strains (Silva et al., 2009; Askari Badouei et al., 2014; Chandran and Mazumder, 2014; Dey et al., 2014; Gargiulo et al., 2014; Chiacchio et al., 2016). Additionally, putative adhesins were detected in STEC and EPEC strains from humans and animals worldwide, including wild birds (Afset et al., 2006; Borges et al., 2012; Cooley et al., 2013; Beraldo et al., 2014; Miko et al., 2014; Akiyama et al., 2016). However, there are no reports of EPEC and STEC strains carrying putative adhesins in pigeons and wild birds from Brazil.

Due to the increased interaction of urban pigeons and wild birds with humans and other animals and the fact that these birds can carry pathogenic microorganisms that pose a risk to public health (Haag-Wackernagel and Moch, 2004; Blyton et al., 2015) we conducted this study to detect and characterize STEC and EPEC strains to determine if those birds can indeed serve as reservoir for diarrheagenic E. coli in Brazil.

\section{Materials and Methods}

\section{Ethics statement}

The study is in accordance with the Ethical Principles in Animal Experimentation, adopted by the Brazilian College of Experimentation (COBEA) and was approved by Animal Experimentation Ethics Committee (CEUA) from São Paulo State University, protocol n0. 22.222/10 on 22 October 2010. 


\section{Sampling and initial procedures}

Samples were collected from 123 free-living wild birds that were treated at the Wildlife Veterinary Hospital in UNESPFCAV, Brazil, from September 2010 to April 2012 ( $n$ oropharynx samples $=123$; $n$ cloaca samples $=123$ ). The birds did not show clinical signs of infectious diseases. They were distributed in 15 orders: Accipitriformes $=2$; Anseriformes $=1$; Cariamiformes $=3$; Cathartiformes $=2$; Charadriiformes $=2$; Columbiformes $=14$; Falconiformes $=9$; Galliformes $=1$; Grui formes $=1$; Passeriformes=10; Pelecaniformes $=1$; Piciformes 6; Psittaciformes $=60$; Strigiformes $=9$; Tinamiformes $=2$. Samples from 100 free-living urban pigeons (Columba livia) captured at São Paulo State University (UNESP), Brazil, from February to April 2012 were also collected ( $n$ oropharynx samples $=100 ; n$ cloaca samples $=100$ ). All the 446 samples were immediately cultured into tubes containing $5 \mathrm{ml}$ of BHI (brain and heart infusion) broth and transported to the laboratory on ice in thermal boxes. The tubes were incubated aerobically overnight at $37^{\circ} \mathrm{C}$, and an aliquot of each culture was stored at $-80^{\circ} \mathrm{C}$.

\section{Detection of STEC and EPEC by PCR}

DNA extraction of the 446 samples incubated overnight was performed by thermal lysis procedure, according to a protocol of the OIE Reference Laboratory for Escherichia coli (EcL - Faculté de Médecine Véterinaire, Université de Montréal) available at www.apzec.ca/en/APZEC/Protocols/pdfs/ ECL_PCR_Protocol.pdf with slight modifications, BHI broth was used instead LB (Luria-Bertani) broth. After preparation of the DNA templates, PCR was performed as described previously (Borges et al., 2012) using primers listed in the supplementary table. Each DNA was screened for three genes that identify the STEC (stx1, stx2) and EPEC (eae) pathotypes. The primers, annealing temperatures, and controls are described in Supplementary data Table S1. Samples that were positive for at least one of the genes were subcultured onto MacConkey agar plates and incubated at $37^{\circ} \mathrm{C}$ for $24 \mathrm{~h}$. From each plate, ten randomly typical colonies of $E$. coli were selected; DNA of each colony was extracted and tested by PCR as described above for the detection of $s t x 1, s t x 2$, and eae. Positive colonies for at least one gene were stored at $-80^{\circ} \mathrm{C}$ as pure cultures for subsequent experiments. This methodology is according to the Reference Laboratory for Escherichia coli [EcL] Université de Montréal (Borges et al., 2012).

\section{Detection of additional virulence genes}

All isolates were tested for nine additional virulence genes by PCR amplification. The primers used are listed in supplementary table. One triplex (iha, toxB, saa) and six monoplex (bfp, ehx $\mathrm{A}, n l e \mathrm{~B}, n l e \mathrm{E}, e s p \mathrm{~A}$, and $\left.l p f \mathrm{~A}_{\mathrm{O} 113}\right)$ PCR procedures were performed. The detection of $b f p$ gene differentiate tEPEC (positive for $b f p$ ) from aEPEC (negative for $b f p$ ).

\section{Determination of phylogenetic group by PCR}

Strains were assigned to one of the four main phylogenetic groups of E. coli (A, B1, B2, or D) by using the triplex PCR targeting chuA, yjaA, and the DNA fragment TSPE4.C2 (Clermont et al., 2000).
Detection of extended-spectrum $\beta$-lactamases (ESBLs) genes and antimicrobial susceptibility test

E. coli isolates were screened for ESBL-genes using PCR as described previously for $b l a_{\text {CTX-M }}$ genotype groups 1, 2, 8, 9 and 25, bla $a_{\mathrm{TEM}}$, bla $a_{\mathrm{SHV}}$ (Dallenne et al., 2010). Sequencing was done at the University of California Berkeley DNA Sequencing Facility (Berkeley, USA). The sequences were compared with those deposited in the National Center for Biotechnology Information (NCBI) database by an updated version of the BLAST program. Antimicrobial disk susceptibility tests were performed using the disk diffusion method (CLSI, 2015). The antimicrobials tested were amikacin $(30 \mu \mathrm{g})$, ampicillin $(10 \mu \mathrm{g})$, cefotaxime $(30 \mu \mathrm{g})$, cefoxitin $(30 \mu \mathrm{g})$, ceftiofur $(30 \mu \mathrm{g})$, ertapenem $(10 \mu \mathrm{g})$, imipenem $(10 \mu \mathrm{g})$, fosfomycin $(200 \mu \mathrm{g})$, gentamicin $(10 \mu \mathrm{g})$, kanamycin $(30 \mu \mathrm{g})$, nalidixic acid $(30 \mu \mathrm{g})$, nitrofurantoin $(300 \mu \mathrm{g})$, norfloxacin $(10 \mu \mathrm{g})$, sulfamethoxazole + trimethoprim $(25 \mu \mathrm{g})$, and tetracycline $(30 \mu \mathrm{g})$.

\section{$O$ and $H$ typing}

Strains were analyzed for $\mathrm{O}$ and $\mathrm{H}$ antigens at the E. coli Reference Center (The Pennsylvania State University, University Park, USA). The $\mathrm{O}$ antigen typing was performed by using antisera produced against serogroups O1-O181 with the exceptions of O14, O31, O47, O72, O93, O94, and $\mathrm{O} 122$ since these serogroups have not yet been designated. The $\mathrm{H}$ antigen typing was performed by the Polymerase Chain Reaction-Restriction Fragment Length Polymorphism (PCR-RFLP) of $f l i C$ gene which encodes flagella.

\section{Pulsed-field gel electrophoresis (PFGE)}

The isolates were subtyped by the standardized rapid PFGE protocol used by laboratories in PulseNet (https://www.cdc. gov/pulsenet/pdf/ecoli-shigella-salmonella-pfge-protocol-508c.pdf). The E. coli chromosomal DNA was digested with $X b a I$. Electrophoresis conditions consisted of an initial pulse time of $2.2 \mathrm{sec}$ and a final pulse time of $54.2 \mathrm{sec}$ at a gradient of $6 \mathrm{~V} / \mathrm{cm}$ and an included angle of $120^{\circ}$ in a CHEF-DRIII PFGE system (Bio-Rad Laboratories). The gels were electrophoresed for $22 \mathrm{~h}$. The similarities of fragments were compared using a Dice coefficient at $1 \%$ tolerance and $0.5 \%$ optimization, and Dendrograms were constructed using the UPGMA clustering method using the BioNumerics version 7.1 (Applied Maths).

\section{Multilocus sequence typing (MLST)}

MLST was performed following the Achtmans's scheme (http://mlst.ucc.ie/mlst/dbs/Ecoli). This scheme is based on the sequencing of the PCR amplification products of $a d k$, fum $\mathrm{C}$, gyr B, icd, $m d h$, purA, and recA (Supplementary data Table S1). DNA template preparation and PCR were conducted as described in the previous section. Sequencing was performed at the University of California Berkeley DNA Sequencing Facility. 


\section{Results}

\section{Isolates harboring virulence genes}

A total of 246 samples from free-living wild birds and 200 samples from free-living urban pigeons were subjected to PCR screening for the detection of st $x 1$, st $x 2$, and eae genes. The number of wild birds samples positive for STEC genes (stx 1 and/or stx 2$)$ and EPEC gene (eae) were $24(9.8 \%)$ and $31(12.6 \%)$, respectively. From these positive samples two $(0.8 \%)$ STEC (stx2+eae-) and five (2.0\%) EPEC isolates were obtained from wild birds, being two aEPEC $(e a e+b f p-)$ and three tEPEC $(e a e+b f p+)$. Regarding the urban pigeons, the number of samples positive for STEC genes (stx 1 and/or st $x 2)$ and EPEC gene (eae) were $1(0.5 \%)$ and $24(12.0 \%)$, respectively. From these positive samples, four (2.0\%) aEPEC $(e a e+b f p-)$ isolates were obtained. These isolates were subjected to a new round of PCR to detect additional virulence genes. The saa gene was the most prevalent in EPEC isolates $(100.0 \%)$, followed by iha (81.8\%), espA (45.5\%), lpfA $\mathrm{A}_{O 113}$ (45.5\%), nleE (45.5\%), and nleB (27.3\%). The most prevalent genes in STEC isolates were saa (100.0\%), lpfA $\mathrm{Ol11}(100.0 \%)$, nleE (100.0\%), iha (50.0\%), and ehxA (50.0\%). All STEC and EPEC isolates were negative for toxB gene and all STEC were negative for $n l e \mathrm{~B}$ and espA. Figure 1 shows the virulence profiles of the tested isolates.

\section{Phylogenetic typing}

Phylogenetic group test showed that one aEPEC and three tEPEC belonged to B2 (44.5\%), three aEPEC belonged to A $(33.3 \%)$ and two aEPEC belonged to B1 (22.2\%) groups, while STEC strains belonged to A (1/50.0\%) and B1 (1/50.0\%) groups. None E. coli belonged to D group (Fig. 1).

\section{Detection of ESBL genes and antimicrobial susceptibility test}

The isolates were subjected to PCR to detect ESBL genes. Sequence analysis of bla $a_{\text {CTX-M }}$ and $b l a_{\text {TEM }}$ genes identified one isolate from wild bird carrying both bla $a_{\mathrm{CTX}-\mathrm{M}-8}$ and bla $a_{\mathrm{TEM}-1}$, while none of them presented blasHv gene. Furthermore, all the isolates were tested against 15 antimicrobial agents. Multidrug resistance, which was defined as resistance against three or more classes of antimicrobials, was associated with $25.0 \%$ of the E. coli isolated from urban pigeons and $57.0 \%$ of the E. coli isolated from wild birds. The isolates from wild birds were more resistant to ceftiofur (71.4\%), nitrofurantoin (57.0\%), kanamycin (42.8\%), tetracycline (42.8\%), ampicillin
(28.6\%), cefotaxime (14.3\%), fosfomycin (14.3\%), nalidixic acid (14.3\%), norfloxacin (14.3\%), and sulfamethoxazole/ trimethoprim (14.3\%). All isolates from wild birds were susceptible to amikacin, cefoxitin, gentamicin, ertapenem, and imipenem. On the other hand the isolates from urban pigeons were more resistant to ceftiofur (100.0\%), cefoxitin (25.0\%), kanamycin $(25.0 \%)$, and nitrofurantoin $(25.0 \%)$. All isolates from urban pigeons were susceptible to ampicillin, amikacin, cefotaxime, ertapenem, imipenem, fosfomycin, gentamicin, nalidixic acid, norfloxacin, sulfamethoxazole + trimethoprim, and tetracycline. Figure 1 shows the resistant profile of each isolate.

\section{$\mathrm{O}$ and $\mathrm{H}$ typing}

The only serogroup detected in the E. coli isolates from urban pigeon was O184; three strains presented a non-typable $\mathrm{O}$ antigen. Regarding the E. coli isolates from wild birds the serogroups detected were $\mathrm{O} 6, \mathrm{O} 48, \mathrm{O} 110$, and $\mathrm{O} 137$. Three strains presented a non-typable $\mathrm{O}$ antigen (Fig. 1).

\section{Pulsed-field gel electrophoresis (PFGE)}

Genetic diversity was analyzed in the 11 strains of $E$. coli that were isolated from free-living wild birds and urban pigeons. PFGE revealed 11 distinct restriction patterns using a difference of a single band as a basis for discriminating between isolates. All isolates were grouped into unique pulsotypes demonstrating a high degree of heterogeneity among STEC and EPEC examined in the study (Fig. 1).

\section{Multilocus sequence typing (MLST)}

MLST was performed in the $11 \mathrm{E}$. coli and revealed six distinct sequence types (ST). The STs found in pigeons were ST28 $(n=1)$, ST40 $(n=1)$, and ST1296 $(n=1)$ and the STs detected in wild birds were ST28 $(n=1)$, ST1423 $(n=1)$, ST2101 $(n=1)$, and ST2678 $(n=1)$. One isolate from pigeons and two isolates from wild birds contained unknown STs (Fig. 1).

\section{Discussion}

In this work it was determined the prevalence of STEC and EPEC strains in wild birds and urban pigeons. The characterization of these strains allowed us to show that these birds can carry human MDR diarrheagenic E. coli.

The prevalence of EPEC and STEC in wild birds and urban
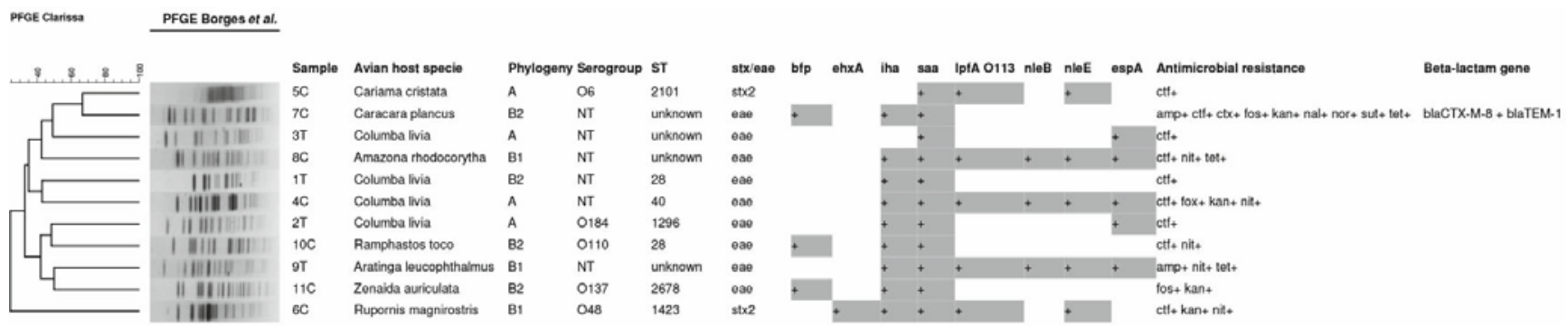

Fig. 1. Dendrogram showing similarity relationship established by PFGE based in the Dice coefficient and clustering by UPGMA. C, cloaca; T, oropharynx; NT, nontypeable. 
pigeons are similar to the ones reported in other studies conducted in these free-living avian species, where frequencies ranged from $0 \%$ to $1.8 \%$ for STEC strains (Kobayashi et al., 2002; Wani et al., 2004; Silva et al., 2009; Caballero et al., 2015; Koochakzadeh et al., 2015) and from 2.8\% to 4.9\% for EPEC strains (Hughes et al., 2009; Silva et al., 2009; Oh et al., 2011; Sacristán et al., 2014).

Genetic analyses showed that the strains in the present study harbored other genes that contribute to virulence, such as saa, iha, $l p f A_{\mathrm{O} 113}, e h x \mathrm{~A}, \operatorname{esp} \mathrm{A}, n l e \mathrm{~B}$, and nle $\mathrm{E}$. These genes had previously been detected in $E$. coli isolated from humans with diarrhea, hemorrhagic colitis, and HUS. Specifically, the nle B and nleE genes have been statistically associated with EPEC strain that causes diarrhea in humans (Jenkins et al., 2003; Afset et al., 2006; Garrido et al., 2006; Bielaszewska et al., 2011; Coombes et al., 2016). To the best of our knowledge, this is the first report of the presence of the $\operatorname{lpf} A_{\mathrm{O} 113}$, saa, espA, nleB, and nleE genes in STEC and EPEC strains isolated from wild birds and urban pigeons from Brazil.

Phylogenetic typing demonstrated that all tEPEC strains from the present study were classified as B2 and one of them was found to harbor the ESBL gene $b l a_{\mathrm{CTX}-\mathrm{M}-8}$ in association with a TEM-1-type penicillinase. It had previously been shown that tEPEC strains might be more virulent than aEPEC strains due to the presence of the EAF plasmid. Since humans are the major natural reservoir for tEPEC (Trabulsi et al., 2002), it suggests that these birds may constitute a reservoir for pathogenic $E$. coli with zoonotic potential.

The fact that MDR strains were found in these birds could be explained by their eating habits, as they can acquire pathogens through food and/or water contaminated with human feces and farm waste. Furthermore, strains of the present study belonged to STs and serogroups that were previously implicated in animal and human diseases (Blanco et al., 2006; Persson et al., 2007; Coque et al., 2008; Dallman et al., 2012; Kang et al., 2014; Maluta et al., 2014; Ferdous et al., 2016), indicating that transmission of $E$. coli between birds and humans might occur and reinforce that wild birds and pigeons may be a reservoir of pathogenic $E$. coli for humans. PFGE analysis showed that E. coli strains isolated from wild birds and pigeons exhibit high heterogeneity. Similar to this result, a number of studies have reported the occurrence of diverse E. coli populations in different hosts and environments (Afset et al., 2006; Ibekwe et al., 2011; Kemmett et al., 2013). The high variability shown by PFGE and the difference in serogroups, virulence genes and antimicrobial profiles demonstrate that there are no prevalent STEC and EPEC clones from these avian hosts.

The results presented here suggest that wild birds and pigeons could act as carriers of multidrug-resistant STEC and EPEC and therefore may constitute a considerable hazard to human health by transmission of these strains to the environment. Besides that, the fact that these pathogens were found in bird species living in rural areas indicates that human activities are disturbing natural environments, representing also a risk to animals in the wild.

\section{Acknowledgements}

This research was supported by grants from São Paulo Research Foundation (FAPESP grant numbers 2008/00417-0, 2010/12002-0 and 2011/06467-2).

\section{References}

Afset, J.E., Bruant, G., Brousseau, R., Harel, J., Anderssen, E., Bevanger, L., and Bergh, K. 2006. Identification of virulence genes linked with diarrhea due to atypical enteropathogenic Escherichia coli by DNA microarray analysis and PCR. J. Clin. Microbiol. 44, 3703-3711.

Akiyama, Y., Futai, H., Saito, E., Ogita, K., Sakae, H., Fukunaga, M., Tsuji, H., Chikahira, M., and Iguchi, A. 2016. Shiga toxin subtypes and virulence genes distributed among Escherichia coli isolated from Cattle. Jpn. J. Infect. Dis. DOI: 10.7883/yoken.JJID. 2016.100.

Askari Badouei, M., Zahraei Salehi, T., Koochakzadeh, A., Kalantari, A., and Tabatabaei, S. 2014. Molecular characterization, genetic diversity and antibacterial susceptibility of Escherichia coli encoding Shiga toxin $2 \mathrm{f}$ in domestic pigeons. Lett. Appl. Microbiol. 59, 370-376.

Beraldo, L.G., Borges, C.A., Maluta, R.P., Cardozo, M.V., Rigobelo, E.C., and de Ávila, F.A. 2014. Detection of Shiga toxigenic (STEC) and enteropathogenic (EPEC) Escherichia coli in dairy buffalo. Vet. Microbiol. 170, 162-166.

Bielaszewska, M., Mellmann, A., Zhang, W., Köck, R., Fruth, A., Bauwens, A., Peters, G., and Karch, H. 2011. Characterization of the Escherichia coli strain associated with an outbreak of haemolytic uraemic syndrome in germany, 2011: A microbiological study. Lancet. Infect. Dis. 11, 671-676.

Blanco, M., Blanco, J.E., Dahbi, G., Alonso, M.P., Mora, A., Coira, M.A., Madrid, C., Juárez, A., Bernárdez, M.I., González, E.A., et al. 2006. Identification of two new intimin types in atypical enteropathogenic Escherichia coli. Int. Microbiol. 9, 103-110.

Blyton, M.D.J., Pi, H., Vangchhia, B., Abraham, S., Trott, D.J., Johnson, J.R., and Gordon, D.M. 2015. The genetic structure and antimicrobial resistance of Escherichia coli and cryptic clades in birds with diverse human associations. Appl. Environ. Microbiol. 81, 5123-5133.

Boerlin, P., McEwen, S.A., Boerlin-Petzold, F., Wilson, J.B., Johnson, R.P., and Gyles, C.L. 1999. Associations between virulence factors of shiga toxin-producing Escherichia coli and disease in humans. J. Clin. Microbiol. 37, 497-503.

Borges, C.A., Beraldo, L.G., Maluta, R.P., Cardozo, M.V., Guth, B.E.C., Rigobelo, E.C., and de Ávila, F.A. 2012. Shiga toxigenic and atypical enteropathogenic Escherichia coli in the feces and carcasses of slaughtered pigs. Foodborne Pathog. Dis. 9, 11191125.

Caballero, M., Rivera, I., Jara, L.M., Ulloa-Stanojlovic, F.M., and Shiva, C. 2015. Isolation and molecular identification of potentially pathogenic Escherichia coli and Campylobacter jejuni in feral pigeons from an urban area in the city of Lima, Peru. Rev. Inst. Med. Trop. São Paulo 57, 393-396.

Chandran, A. and Mazumder, A. 2014. Occurrence of diarrheagenic virulence genes and genetic diversity in Escherichia coli isolates from fecal material of various avian hosts in British Columbia, Canada. Appl. Environ. Microbiol. 80, 1933-1940.

Chiacchio, R.M.G.D., Cunha, M.P.V., Sturn, R.M., Moreno, L.Z., Moreno, A.M., Pereira, C.B.P., Martins, F.H., Franzolin, M.R., Piazza, R.M.F., and Knöbl, T. 2016. Shiga toxin-producing Escherichia coli (STEC): Zoonotic risks associated with psittacine pet birds in home environments. Vet. Microbiol. 184, 27-30.

Clermont, O., Bonacorsi, S., and Bingen, E. 2000. Rapid and simple 
determination of Escherichia coli phylogenetic group. Appl. Environ. Microbiol. 66, 4555-4558.

CLSI. 2015. Performance Standards for Antimicrobial Susceptibility Testing; Twenty-Fifth Informational Supplement. CLSI Document M100-S25.

Cooley, M.B., Jay-Russell, M., Atwill, E.R., Carychao, D., Nguyen, K., Quiñones, B., Patel, R., Walker, S., Swimley, M., Pierre-Jerome, E., et al. 2013. Development of a robust method for isolation of Shiga toxin-positive Escherichia coli (STEC) from fecal, plant, soil and water samples from a leafy greens production region in California. PLoS One 8, e65716

Coombes, B.K., Wickham, M.E., Mascarenhas, M., Gruenheid, S., Finlay, B.B., and Karmali, M.A. 2008. Molecular analysis as an aid to assess the public health risk of non-O157 Shiga toxinproducing Escherichia coli strains. Appl. Environ. Microbiol. 74, 2153-2160.

Coque, T.M., Baquero, F., and Canton, R. 2008. Increasing prevalence of ESBL-producing Enterobacteriaceae in Europe. Euro Surveill. 13, 5437-5453.

Dallenne, C., Da Costa, A., Decré, D., Favier, C., and Arlet, G. 2010. Development of a set of multiplex PCR assays for the detection of genes encoding important $\beta$-lactamases in Enterobacteriaceae. J. Antimicrob. Chemother. 65, 490-495.

Dallman, T., Smith, G.P., O'Brien, B., Chattaway, M.A., Finlay, D., Grant, K.A., and Jenkins, C. 2012. Characterization of a verocytotoxin-producing enteroaggregative Escherichia coli serogroup O111: H21 strain associated with a household outbreak in northern Ireland. J. Clin. Microbiol. 50, 4116-4119.

Dey, R.K., Khatun, M.M., Islam, M.A., and Hosain, M.S. 2014. Prevalence of multidrug resistant Escherichia coli in pigeon in Mymensingh, Bangladesh. Microb. Health 2, 5-7.

Ferdous, M., Friedrich, A.W., Grundmann, H., de Boer, R.F., Croughs, P.D., Islam, M.A., Kluytmans-van den Bergh, M.F.Q., Kooistra-Smid, A.M.D., and Rossen, J.W.A. 2016. Molecular characterization and phylogeny of shiga toxin-producing Escherichia coli isolates obtained from two dutch regions using whole genome sequencing. Clin. Microbiol. Infect. 22, 642.e1-9.

Gargiulo, A., Russo, T.P., Schettini, R., Mallardo, K., Calabria, M., Menna, L.F., Raia, P., Pagnini, U., Caputo, V., Fioretti, A., et al. 2014. Occurrence of enteropathogenic bacteria in urban pigeons (Columba livia) in italy. Vector Borne Zoonotic Dis. 14, 251-255.

Garrido, P., Blanco, M., Moreno-Paz, M., Briones, C., Dahbi, G., Blanco, J., Blanco, J., and Parro, V. 2006. STEC-EPEC oligonucleotide microarray: A new tool for typing genetic variants of the LEE pathogenicity island of human and animal Shiga toxinproducing Escherichia coli (STEC) and enteropathogenic E. coli (EPEC) strains. Clin. Chem. 52, 192-201.

Haag-Wackernagel, D. and Moch, H. 2004. Health hazards posed by feral pigeons. J. Infect. 48, 307-313.

Hughes, L., Bennett, M., Coffey, P., Elliott, J., Jones, T., Jones, R., Lahuerta-Marin, A., McNiffe, K., Norman, D., and Williams, N. 2009. Risk factors for the occurrence of Escherichia coli virulence genes eae, stx 1 and stx 2 in wild bird populations. Epidemiol. Infect. 137, 1574.

Ibekwe, A.M., Murinda, S.E., and Graves, A.K. 2011. Genetic diversity and antimicrobial resistance of Escherichia coli from human and animal sources uncovers multiple resistances from human sources. PLoS One 6, e20819.
Jenkins, C., Perry, N.T., Cheasty, T., Shaw, D.J., Frankel, G., Dougan, G., Gunn, G.J., Smith, H.R., Paton, A.W., and Paton, J.C. 2003. Distribution of the saa gene in strains of Shiga toxin-producing Escherichia coli of human and bovine origins. J. Clin. Microbiol. 41, 1775-1778.

Kang, E., Hwang, S.Y., Kwon, K.H., Kim, K.Y., Kim, J.H., and Park, Y.H. 2014. Prevalence and characteristics of shiga toxin-producing Escherichia coli (STEC) from cattle in Korea between 2010 and 2011. J. Vet. Sci. 15, 369-379.

Kaper, J.B., Nataro, J.P., and Mobley, H.L.T. 2004. Pathogenic Escherichia coli. Nat. Rev. Microbiol. 2, 123-140.

Kemmett, K., Humphrey, T., Rushton, S., Close, A., Wigley, P., and Williams, N.J. 2013. A longitudinal study simultaneously exploring the carriage of APEC virulence associated genes and the molecular epidemiology of faecal and systemic E. coli in commercial broiler chickens. PLoS One 8, e67749.

Kobayashi, H., Pohjanvirta, T., and Pelkonen, S. 2002. Prevalence and characteristics of intimin- and shiga toxin-producing Escherichia coli from gulls, pigeons and broilers in Finland. J. Vet. Med. Sci. 64, 1071-1073.

Koochakzadeh, A., Askari Badouei, M., Zahraei Salehi, T., Aghasharif, S., Soltani, M., and Ehsan, M. 2015. Prevalence of shiga toxin-producing and enteropathogenic Escherichia coli in wild and pet birds in Iran. Rev. Bras. Cienc. Avic. 17, 445-450.

Maluta, R.P., Logue, C.M., Casas, M.R.T., Meng, T., Guastalli, E.A.L., Rojas, T.C.G., Montelli, A.C., Sadatsune, T., de Carvalho Ramos, M., Nolan, L.K., et al. 2014. Overlapped sequence types (STs) and serogroups of avian pathogenic (APEC) and human extra-intestinal pathogenic (EXPEC) Escherichia coli isolated in Brazil. PLoS One 9, e105016.

Miko, A., Rivas, M., Bentancor, A., Delannoy, S., Fach, P., and Beutin, L. 2014. Emerging types of Shiga toxin-producing E. coli (STEC) O178 present in cattle, deer, and humans from Argentina and Germany. Front. Cell. Infect. Microbiol. 4, 78.

Oh, J.Y., Kang, M.S., Hwang, H.T., An, B.K., Kwon, J.H., and Kwon, Y.K. 2011. Epidemiological investigation of eaeA-positive Escherichia coli and Escherichia albertii strains isolated from healthy wild birds. J. Microbiol. 49, 747-752.

Persson, S., Olsen, K.E.P., Ethelberg, S., and Scheutz, F. 2007. Subtyping method for Escherichia coli shiga toxin (verocytotoxin) 2 variants and correlations to clinical manifestations. J. Clin. Microbiol. 45, 2020-2024.

Sacristán, C., Esperón, F., Herrera-León, S., Iglesias, I., Neves, E., Nogal, V., Muñoz, M., and de la Torre, A. 2014. Virulence genes, antibiotic resistance and integrons in Escherichia coli strains isolated from synanthropic birds from Spain. Avian Pathol. 43, 172175.

Silva, V., Nicoli, J., Nascimento, T., and Diniz, C. 2009. Diarrheagenic Escherichia coli strains recovered from urban pigeons (Columba livia) in Brazil and their antimicrobial susceptibility patterns. Curr. Microbiol. 59, 302-308.

Trabulsi, L.R., Keller, R., Tardelli Gomes, T.A. 2002. Typical and atypical enteropathogenic Escherichia coli. Emerg. Infect. Dis. 8, 508-513.

Wani, S.A., Samanta, I., Bhat, M.A., and Nishikawa, Y. 2004. Investigation of shiga toxin-producing Escherichia coli in avian species in India. Lett. Appl. Microbiol. 39, 389-394. 